\title{
Defining child exposure to domestic violence: Lessons from a historical review of the literature
}

\author{
Stephenie Howard ${ }^{1}$ \\ ${ }^{1}$ Norfolk State University \\ Received 29 June 2021 \\ Accepted for publication 6 October 2021 \\ Published 18 December 2021
}

\begin{abstract}
'Child witnesses of domestic violence' policies and practices in the United States have been fraught with conceptual challenges that limit their implementation. Such limitations are evident in the case of Minnesota, which amended its definition of child neglect to include a child's exposure to family violence, only to later repeal this amendment in response to pressure from child welfare administrators and domestic violence advocates (Edleson, Gassman-Pines and Hill, 2006; Kantor and Little, 2003). The conceptual flaws are also evident in disparities across state statutes for definitions of child witnesses of domestic violence and the legal penalties it carries (Child Welfare Information Gateway, 2021). To enhance the integrity of child witnesses of domestic violence policies and practices, critical attention is needed to clarify and refine the central construct. Pursuant to this goal, this conceptual paper analyzes and synthesizes the history of child welfare. It demonstrates how child witnesses of domestic violence became a social and legal problem. The author traces the evolution of child welfare as a concept and provides new insights. The author also sheds light on the driving forces of child welfare policies and practices. The paper begins in the Colonial Ages, which gave roots to the contemporary child welfare system. The author describes the early development of child welfare leading to contemporary practice. The paper ends by making evidence-based recommendations for constructing child welfare policies that enhance the safety of children exposed to domestic violence using least restrictive interventions.
\end{abstract}

Keywords: child witnesses of domestic violence, family violence, intimate partner abuse, child maltreatment, child welfare

\section{Introduction}

Children who live in homes where domestic violence occurs learn indirectly about acts of violence at best and at worst are present when the acts occur. They are likely to suffer psychological or physical injuries from exposure to domestic violence. An estimated $20 \%$ of child homicide victims in the US are the result of domestic violence exposure (Adhia et al., 2019). Yet, US states have been slow and inconsistent in recognizing the potential harm that comes to children exposed to domestic violence. Only 26 states, and Puerto Rico, explicitly define child exposure to domestic violence as a civil and/or criminal offense (Child Welfare Information Gateway, 2021). Some states such as Minnesota even repealed their child witnesses of domestic violence laws following backlash from child welfare administrators and domestic violence advocates (Edleson, Gassman-Pines and Hill, 2006; Kantor and Little, 2003). Among the states with existing statutes, the circumstances that constitute exposure to domestic violence as well as the legal consequences vary greatly (Child Welfare Information Gateway, 2021). There is a great need to refine existing statutes so that they are more informed and agreeable.

Toward this goal, this paper reports on a historical review of the literature on the development of child welfare in the US to understand the underlying philosophical views and values. The paper traces the evolution of child welfare as a concept and provides new insights, and demonstrates how child witnesses of domestic violence became a social and legal problem. It also traces the history from the Colonial Era to contemporary practices, while it sheds light on the driving forces of child welfare policies and practices and provides insight into the theoretical underpinnings. Lastly, 
recommendations for policies and practices for children exposed to domestic violence are made.

\section{Foundational background of child welfare}

This paper begins by examining the cultural assumptions and legal practices surrounding parent-child relationships in the Colonial Ages to understand the philosophical underpinnings of child welfare policies and practices. It is important to note that patrilineal and patriarchal laws and customs governed the colonists. Colonists believed that fathers had absolute power over their households (Mason, 1994; Woodhouse, 1992). As such, fathers had the right to treat their children as they saw fit. Fathers typically consigned their children to labor so that they could benefit from their wages (Mason, 1994; Woodhouse, 1992). This custom left orphans and other left children without parents to be exploited for their labor. Mason (1994) recounts that many children without parents came to the new colonies in America as indentured servants. Colonists routinely separated children born out-of-wedlock from their mothers and bound them out. They also removed children born into slavery from their parents and sold them to slave owners (Mason, 1994).

The servitude of children was based, in part, on the critical need for labor in the new colonies. Colonists viewed children as valuable workers in the labor-scarce colonies (Mason, 1994). In this context, fathers regarded their children as valuable assets for which they had personal involvement. In exchange for provisions and protection, fathers claimed the wages children received for their services and labor (Woodhouse, 1992). As follows, fathers placed children under a legal obligation to work, or traded, married-off, or sold them into slavery.

Common law supported child labor (Mason, 1994). Fathers had the right to use their children at their discretion. In like manner, fathers had the legal authority to administer corporal punishment to their children (Woodhouse, 1992). Colonists viewed corporal punishment as a parental right (Mason, 1994). Because children were akin to chattel, parents, fathers in particular, had the freedom to decide how to treat them. As a result, child physical abuse, neglect, and sexual assault were likely prevalent, though no accurate prevalence rates can be established at present.

\section{Early roots of child welfare}

The first iteration of child welfare traces back to the selfproclaimed "child-savers" of the 1850s (Woodhouse, 1992). Early child-savers removed immigrant children from impoverished homes and placed them in lodging houses, foster homes, and industrial schools (Woodhouse, 1992). They justified intervention on the basis of a parent's failure to live up to established housing standards (Woodhouse, 1992). Later child savers provided aid to poor White widows and single mothers (Roberts, 2002). State policies came to conflate child neglect and poverty such that children dependent on the public for support and those living without parental care were treated the same under the law (Roberts, 2002). There was a general consensus that child maltreatment stemmed from poverty, and indulgent children were to be provided for by the community. Notably, however, child welfare only extended to White children (Roberts, 2002). Black children and families were excluded from services in practice and effect because they were not deemed part of the community (Roberts, 2002).

A natural byproduct of the work of child savers was child labor advocacy because they viewed poverty as the grounds for child labor (Woodhouse, 1992). The use of children's labor in the workforce continued from Colonial Era to the Industrial Revolution. Woodhouse (1992, p. 1059) states that 'one-third of the workforce in southern textile mills was children aged ten to thirteen'. Child savers took issue with the dangerous conditions in which children were working in the factories (Woodhouse, 1992). They mounted a campaign to bring the harsh work conditions of children to public attention (Woodhouse, 1992). Thanks to the work of the child rights movement, sentiments about the role of children and their rights began to change. Their work culminated in the formation of the National Child Labor Committee in 1909 and the Children's Bureau within the Labor Department a few years following (Woodhouse, 1992). The Children's Bureau would go on to advance titles of the Social Security Act of 1935, which would lay the foundation for today's federal welfare programs for children and their families living in poverty (Myers, 2008).

\section{The emergence of the medical model of child welfare}

Efforts to address the safety and well-being of children would remain largely limited to poverty and poverty adjacent issues until the late $20^{\text {th }}$ century. Roberts (2002) explains that, because child rights activists linked child welfare to poverty, in the 1970s, when the war on poverty came under attack by the public, interest in child welfare began to wane. In response, child welfare advocates took measures to dissociate child welfare from poverty programs. They reframed child maltreatment as a symptom of individual pathology. In effect, child welfare policies and services began to cut back on aid to families and raise the penalties to families. At the same time, child welfare saw a drastic rise in the number of Black 
children receiving services. This time marked the beginning of the racial disproportionality in child welfare that is evident even today (Roberts, 2002). The 1970s represented a new era in child welfare that was overly punitive toward parents, Black parents in particular - referred for services.

Concurrent to the shifting tide of child welfare philosophy, Kempe and colleagues published the seminal article in the Journal of the American Medical Association introducing "the battered child syndrome" as a medical condition (as cited in Parton, 1979). The article addressed the reluctance of the medical community to acknowledge the problem of child maltreatment, identified child maltreatment as a major cause of death and significant injury in children, and recommended that medical professionals report child maltreatment to the proper authorities (Parton, 1979). Kempe coupled his paper with a three-hour plenary session for the 1961 annual meeting of the American Academy of Pediatrics (Krugman, 2018). A multidisciplinary team presented medical findings and the incidence of child maltreatment. Invited press broadcasted the story, leading to national attention (Krugman, 2018).

What followed was a watershed of research on the adverse effects of child abuse on children's physical health. National news outlets made headlines of abuse cases, fueling public interest on the issue (Myers, 2008). This discourse helped to reshape public perceptions about the relationship between children and their parents. Patriarchal beliefs gave way to the egalitarian family model. The public increasingly viewed parents as agents or trustees on behalf of children, and the limits of these bounds began to take shape (Montgomery, 1988). It became widely recognized that parents are entrusted to faithfully administer the affairs of children, and intervention is needed when they falter in this duty. In this way, a medical model of child welfare came to be, with the assumption that parents who abuse their children are pathological and professionals can and should treat child maltreatment. The medical model is best defined as a pathologic approach that 'emphasizes the individual as the source of problem and target of treatment' (Sarri and Finn, 1992, p. 225).

The new interpretation of child maltreatment necessitated a new approach to child welfare. As such, the public called for formalized state intervention. In response, the 1962 amendment of the Social Security Act included an agreement to make child welfare services available statewide over the subsequent 13 years (Myers, 2008). The first major development toward this goal was the passage of the Child Abuse Prevention and Treatment Act (CAPTA) of 1974 (Myers, 2008). Myers (2008) writes that CAPTA authorized federal funds to improve the state response to physical abuse and neglect to include improving investigation and reporting. In addition, CAPTA provided funds for training and related programs. The National Center on Child Abuse and Neglect was developed to administer CAPTA (Myers, 2008). Thus, the 1970s and 1980s saw the development of formalized child abuse and neglect policies.

\section{The development of family-centered strengths- based child welfare model}

Congress passed the Adoption Assistance and Child Welfare Act of 1980 (AACWA) requiring states to make "reasonable efforts" to avoid removing children from maltreating parents. In addition, this act supported the objective of strengthening families to avoid the removal of children and reduce their time in care (Allen and Petre, 1998). AACWA ushered in family preservation policies (Myers, 2008). In the 1980s, pilot studies of family-centered interventions and programs emerged (Jarpe-Ratner and Smithgall, 2017). These interventions and programs included family preservation services, intensive in-home services, and family-centered, neighborhood-based services. They helped to facilitate a new practice paradigm in child welfare - familycentered, strengths-based services (Jarpe-Ratner and Smithgall, 2017; Xu, Ahn and Keyser, 2020). Familycentered, strengths-based services are a set of theoretical principles guiding child welfare policies and practices. Under this framework, public child welfare agencies strive to tailor services to meet the needs of individual families, preserve families whenever possible, partner with families to ensure children's safety and wellbeing and fortify internal strengths and external resources to support family functioning. This approach also expanded on the unit of attention to include the whole family system and explicitly recognized the crucial role of the family in children's development (Allen and Petre, 1998; Reid-Merritt, 2010). The promotion of kinship care, the practice of relatives caring for children in loco parentis is also an outgrowth of the family-focused, strengths-based philosophy (Reid-Merritt, 2010). Taken as a whole, the contemporary developments in child welfare reflect a deliberate and explicit move away from an emphasis on punishment and family disruption toward family preservation.

\section{Including child sexual abuse in child welfare}

Notably, child sexual abuse was not part of the early child welfare discourse (Myers, 2008). The overlook of child sexual abuse can be attributed to early psychological theories. As a leading example, Azzopardia, Alaggiab and Fallon (2018) provide that Freud's seduction theory from the 1890s posited that hysteria is a manifestation of repressed child sexual abuse trauma. In response to the backlash against the notion that 
children experience sexual abuse, Freud reversed his statements (Azzopardia, Alaggiaband Fallon, 2018). He indicated that the childhood sexual assaults that he had previously reported were false memories in defense against memories of their own childish sexual activities (Jung, 1916; Olafson, Corwinand Summit, 1993). After reframing his clinical observations as such, he theorized that variations and manifestations of sexual activity in children, while not comparable to the adult sexuality, were normal and commonplace (Jung, 1916).

Freud went on to advance the Oedipus complex, suggesting that children have an innate unconscious desire for a sexual relationship with their parent of the opposite sex (Azzopardi, Alaggiaand Fallon, 2018) and wish to replace the same-sex parent (Johnson, 2016). This popular theory effectively invalidated reports of child sexual abuse as wishful fantasies for sexual attention (Azzopardi, Alaggiaand Fallon, 2018; Olafson, Corwinand Summit, 1993). While psychologists continued to debate the issue, the general consensus was that child sexual abuse was normal and benign and that children were often complicit in their sexual abuse (Olafson, Corwinand Summit, 1993).

Olafson, Corwin and Summit (1993) indicate that feminists continued Freud's earlier work and sided with the psychologists who condemned child sexual abuse as an offense against innocent children. They called attention to the prevalence of child sexual assault as a function of patriarchy and sexism. In response to the feminist critique, mental health professionals in the 1930s to 1950 s reframed sex abusers as 'radically different from other men, pathological, and properly the province of the treating professionals' (Olafson, Corwin and Summit, 1993, p. 13). Subsequently, a popular narrative took shape with hundreds of American newspapers and magazines perpetuating the myth that strangers were the dominant perpetrators of sex crimes. This discourse effectively concealed the predominance of sexual assault occurring within the family. Child victims of sexual abuse were also relabeled as sex delinquents or participating victims, and incest was constructed to implicate child victims as being seduced by their parents. What resulted was the passage of sex crimes legislation and policies mandating special treatment in mental institutions for "“sexual psychopaths"” (Olafson, Corwinand Summit, 1993, p. 14). There was little protection or discussion about child sexual assault by caregivers.

In the shadows of the mainstream narrative of "stranger danger," researchers began to document that sexual abuse within the family is harmful to the psyche of children (Hudson, 1992; Myers, 2008). Researchers documented fear and stress responses to sexual contact with adults in childhood and the long-term effects of child sexual abuse (Olafson, Corwinand Summit, 1993). Research in the 1950s focused on maternal neglect or failure to protect their children from sexual abuse (Olafson, Corwinand Summit, 1993), but research in the 1970s and 1980s emphasized the harm caused by the abuser (Hudson, 1992; Myers, 2008; Olafson, Corwinand Summit, 1993). This research propelled child sexual abuse into the child welfare paradigm. Child sexual abuse was finally formally recognized as a form of child maltreatment in 1974 with CAPTA, and mandatory reporting laws for child sexual abuse were put in place (Myers, 2008). Consistent with the leading constructions of child maltreatment at the time, perpetrators of child sexual abuse were interpreted as pathological, and non-offending parents were viewed as deficient and remiss in their duties as caregivers.

\section{The inclusion of child witnesses of domestic violence in child welfare}

Child witnesses of domestic violence were the last form of child maltreatment to be formally recognized. It would take twenty years after the 1974 child welfare policies for policymakers to formally establish the inextricable relationship between domestic violence and child maltreatment. Again, the media was instrumental in bringing light to the fact that children often witness domestic violence. They were dubbed the "silent" or "forgotten" victims of domestic violence (Edelson, 1999). The widespread public attention led to a surge of research on child witnesses of domestic violence (Kolbo, Blakelyand Engleman, 1996). In 1999, Edelson cited 84 existing studies on the effect of domestic violence on children's development. The review of the literature documented problems associated with behavioral, emotional, and cognitive functioning as well as long-term developmental issues among children exposed to domestic violence. Researchers also documented that children are often witnesses of the abuse, putting them at risk for physical harm (Holden, 2003). In addition, this research established that child exposure to domestic violence was a prevalent phenomenon (Edelson, 1999). It set the stage for the development of policies and practices for children's exposure to domestic violence.

Following the language and philosophy of child maltreatment at the time, child witnesses of domestic violence discourse took a medical model, indicating exposure to be deleterious to children's wellbeing and warranting state intervention. Policymakers used the body of evidence to support criminal and civil policies for intervening in the lives 
of children exposed to domestic violence (Edelson, 1999). In 1992, CAPTA was amended to include the Child Abuse, Domestic Violence, Adoption, and Family Services Act, which added State domestic violence coalitions under State family violence programs and allocated funds for domestic violence programs and interventions. This law put public child welfare agencies in the position to protect children exposed to domestic violence. In many cases, it resulted in children being removed from homes where domestic violence occurred and separated from their victimized, non-offending parents. Drake and Johnson-Reid (2018) explain that a mother who does not intervene to protect a child from an intimate partner may be found by the child protective agency to be "failing to protect" the child. In this way, state statutes identified non-offending parents who are victims of abuse as perpetrators of child maltreatment.

The implication of domestic violence victims in child maltreatment in state statutes created conflict between child welfare agencies and domestic violence agencies. To remedy this issue, the CAPTA Reauthorization Act of 2010 explicitly supported meaningful collaborations between child protective service entities and domestic violence service entities to improve investigation, intervention, and services for child witnesses of domestic violence. The US Senate Committee on Health, Education, Labor, and Pensions (2010), which approved the bill, made explicit their view that child exposure to domestic violence should not be the sole determinant for removal of a child from their home. They explained that separating children from their non-offending, victimized parent runs the risk of exacerbating the child's psychological injuries. They further encouraged states to invest in best practices for early intervention of child witnesses of domestic violence (US Senate Committee on Health, Education, Labor, and Pensions, 2010). Their justification followed the leading family-focused model of child welfare.

The Massachusetts Department of Social Services was one of the first public agencies to address domestic violence as a child welfare issue (Findlater and Kelly, 1999). In 1992, they instituted a protocol for assessing and intervening in cases involving domestic violence. Four states-Alaska, Georgia, Utah, and Minnesota-followed in redefining domestic violence in the presence of a child as a form of child maltreatment (Kantor and Little, 2003). Minnesota was one of the states at the forefront of this movement (Edleson, Gassman-Pinesand Hill, 2006; Kantor and Little, 2003). In 1999, several committees of the 1999 Minnesota legislature chose the goal of improving child protective services statewide (Edleson, Gassman-Pinesand Hill, 2006). That year, the legislative session heard testimony from academic scholars on the effects of exposure to adult domestic violence on child development, leading to the amendment of the definition of child neglect to include a child's exposure to family violence (Edleson, Gassman-Pinesand Hill, 2006).

Edleson, Gassman-Pines and Hill (2006) indicate that, shortly after its implementation, Minnesota's statutes were criticized. Domestic violence advocates took issue with the expanded definition of child abuse, as it implicated victims in causing harm to children and failed to provide needed services. In addition, public child welfare agencies saw a sizable increase in referrals for child exposure to domestic violence that did not rise to the level of abuse. The agencies were unable to meet the new demands, as the policy did not appropriate additional funding to respond to the increased demand. In response, a coalition of child welfare administrators and domestic violence advocates successfully lobbied for the repeal of exposure to domestic violence as a form of child maltreatment (Edleson, Gassman-Pinesand Hill, 2006). The effects of these actions are still evident today, as there are currently no civil or criminal child witnesses to domestic violence statutes in Minnesota (Child Welfare Information Gateway, 2021).

Research from the Child Welfare Information Gateway (2021) shows that Minnesota is among the 24 states that do not have civil or criminal statutes for child witnesses of domestic violence. The remaining 26 states, and Puerto Rico, impose criminal and civil penalties for acts of domestic violence witnessed by children. The policies reflect the dominant sentiment that violence in homes is harmful to children's health and safety. Though, there is less agreement regarding what constitutes witnessed and the legal consequences it carries. Some states interpret child witnesses as those who are physically present or can "overhear the act of violence". Others have more broad definitions to include acts of violence occurring in a residential unit or to an individual related to the victim or perpetrator of the violence whether the child is present or can see the commission of the offense. Additionally, child exposure to domestic violence may be an aggravating circumstance carrying more severe penalties or a separate crime. There are also different legal consequences such as mandated individual counseling or abuse intervention (Child Welfare Information Gateway, 2021). The wide interpretation of what constitutes exposure and the disparities in the legal consequences are emblematic of the lack of clarity in defining this type of child maltreatment.

\section{Discussion}

In the patriarchal sociopolitical climate of the Colonial Period, children had little rights or protections. Colonists 
believed that fathers had the right to treat children at their own discretion. This led to industrial factories overrun with minor children. Concerns for the safety and well-being of children working in factories fueled calls for child labor laws and aid to impoverished families to minimize the need for child labor. These efforts ushered in the concept of child's rights. However, the concept was largely limited to the context of labor and living conditions. The public did not formally recognize child maltreatment by caregivers as a public issue until the late twentieth century. It took a concerted effort by a small segment of rank-and-file members who were determined to bring to light the issue of child maltreatment. They were successful in presenting child maltreatment as a medical issue that trained professionals should treat. As such, child welfare began as a medical model. Over time, it evolved to a family-centered, strengths-based framework.

Like child sexual abuse, child witness of domestic violence was introduced as a social and legal problem during the era of the medical model of child welfare. This resulted in children being removed from their non-offending mothers who were victims of domestic violence. With the introduction of family-focused practice models, these practices came under scrutiny. Child welfare agencies have since been encouraged to work collaboratively with domestic violence agencies. Still, statutes continue to be rooted in a medical model of child witnesses of domestic violence, which limits their implementation, as was seen in Minnesota. As Edelson (1999) points out, current statutes wrongfully implicate victims in causing harm to their children, ignore their efforts to create safety for their children, and overgeneralize the causal effects of witnessing domestic violence on children. Attention is needed to refine child witnesses of domestic violence statutes and align them with the current model in child welfare that is the family-focused strengths-based model.

\subsection{Policy recommendations}

Following the prevailing view of child welfare, state policies and practices for child exposure to domestic violence should be grounded in a family-focused, strengths-based model. These policies should focus on family preservation whenever possible. Because caregivers are important resources to children, policies ought to avoid implicating the non-offending caregiver in child maltreatment. There should be clear language that identifies the perpetrator of abuse as the offending party.

In addition, child welfare agencies should partner with the family and build on their strengths and resources. Notably, this is a strong departure from the medical model of child welfare. Intervention is needed, but states should avoid excessive penalties for child exposure to domestic violence. States should emphasize partnering with families and connecting them with community support services to prevent child maltreatment or family disruption. Additionally, child welfare agencies should establish clear protocols for what types of interventions are needed based on the assessment of risk. Ideally, child welfare agencies should move toward standardizing these protocols.

Child welfare agencies should also have clear assessment guidelines for understanding and identifying domestic violence exposure as a threat to children's safety. State statutes should recognize the proximal factors or conditions that put children at increased risk of harm. This may include: the child's proximity to victim when the violence occurred, whether the child attempted to intervene in the altercation, whether weapons/objects were used in a threatening or intimidating manner, whether there was property was damaged during the altercation, the type (strangulation, pushing, hitting) and severity of the altercation, and whether the child is fearful of the perpetrator (Henry, 2018).

Definitions of child exposure to domestic violence in state statutes should be sufficiently broad to cover both direct and indirect exposure. Statutes should recognize that children who are present when violence occurs might sustain injury as passive bystanders or in their efforts to intervene in the altercation (Henry, 2018). Statutes should also recognize that learning indirectly about acts of violence might be traumatic (Howard, 2021). They may learn about domestic violence by overhearing the details of the altercation (Dalgaar et al., 2016), witnessing the aftermath of the violence, observing injuries or the distressed effect in the victim (Thornton, 2014), and/or unwittingly participating in trauma reenactments (Ancharoff, Munroe and Fisher, 1998). Taken together, statutes should recognize children's vulnerability to domestic violence whether they are present when the violence occurs.

\section{Conclusion}

This paper has outlined the evolution of child welfare in order to highlight the underlying models and drivers. The author has demonstrated that child welfare has evolved to a family-focused strengths-based model. As such, child witnesses of domestic violence statutes should similarly follow a family-focused strengths-based practice model. They should avoid implicating the non-offending, victim caregiver in causing harm to children. They should clearly outline assessment and intervention protocols that preserve the family integrity. They should include direct and indirect forms of exposure and highlight the proximal risk factors for harm to children. Once definitions of children's exposure to domestic 
violence are aligned with the prevailing model, laws for civil and criminal penalties and child welfare policies can be refined and strengthened to better serve children and families.

\section{References}

Adhia, A., Austin, S.B., Fitzmaurice, G.M. and Hemenway, D. (2019) 'The role of intimate partner violence in homicides of children aged 2-14 years', American Journal of Preventive Medicine, 56(1), pp.38-46.

Allen, R.I. and Petre, C.G. (1998) 'Rethinking familycentered practice', American Journal of Orthopsychiatry, 68(1), pp.4-15. https://doi.org/10.1037/h0080265

Ancharoff, M.R., Munroe, J.F. and Fisher, L.M. (1998) 'The legacy of combat trauma: Clinical implications of intergenerational transmission' in Danieli, Y. (ed.) International handbook of multigenerational legacies of trauma. New York: Plenum Press, pp.257-276.

Azzopardi, C., Alaggia, R. and Fallon, B. (2018) 'From Freud to feminism: Gendered constructions of blame across theories of child sexual abuse', Journal of Child Sexual Abuse, 27(3), pp.254-275.

Child Abuse, Domestic Violence, Adoption, and Family Services Act 1992

Child Abuse Prevention and Treatment Act (CAPTA) Reauthorization Act 2010

Child Abuse Prevention and Treatment Act (CAPTA) 1974

Child Welfare Information Gateway. (2021) Child witnesses to domestic violence. Washington, DC: Children's Bureau

Dalgaard, N.T., Todd, B.K., Daniel, S.I. and Montgomery, E. (2016) 'The transmission of trauma in refugee families: Associations between intra-family trauma communication style, children's attachment security and psychosocial adjustment', Attachment and Human Development, 18(1), pp.69-89.

Drake, B. and Johnson-Reid, M. (2018) 'Defining and Estimating Child Maltreatment' in Kilka, J.B. and Conte, J.R. (eds.). The APSAC Handbook on Child Maltreatment. 4th ed. Thousand Oaks, CA: Sage Publications, pp.14-33.

Edleson, J.L. (1999) 'Children's witnessing of adult domestic violence', Journal of interpersonal Violence, 14(8), pp.839-870.

Edleson, J.L., Gassman-Pines, J. and Hill, M.B. (2006) 'Defining child exposure to domestic violence as neglect: Minnesota's difficult experience', Social Work, 51(2), pp.167-174.
Findlater, J.E. and Kelly, S. (1999) 'Child protective services and domestic violence.' The Future of Children, 9(3), pp.84-96.

Henry, C. (2018) 'Exposure to domestic violence as abuse and neglect: Constructions of child maltreatment in daily practice', Child Abuse and Neglect, 86, pp.79-88.

Holden, G.W. (2003) 'Children exposed to domestic violence and child abuse: Terminology and taxonomy', Clinical Child and Family Psychology Review, 6(3), pp.151-160.

Howard, S. (2021) 'A causal model of children's vicarious traumatization', Journal of Child and Adolescent Trauma, pp.1-12.

Hudson, A. (1992) 'The child sexual abuse 'industry' and gender relations in social work' in. Day, L and Langan, M. (eds.). Women, oppression and social work: Issues in antidiscriminatory practice. New York, NY: Routledge, pp.129-148.

Jarpe-Ratner, E. and Smithgall, C. (2017) 'Supporting strengths-based child welfare practice through a dual professional family assessment program', Journal of Family Social Work, 20(4), pp.271-287.

Johnson, A.L. (2016) 'Psychoanalytic theory' in Capuzzi, D. and Stauffer, M.D. (eds.), Counseling and psychotherapy: Theories and interventions. 6th ed. Alexandria, VA: American Counseling Association, pp.73-97.

Jung, C.G. (1916) Psychology of the unconscious: A study of the transformations and symbolisms of the libido, A contribution to the history of the evolution of thought. New York, NY: Moffat, Yard, and Co

Kantor, G.K., and Little, L. (2003) 'Defining the boundaries of child neglect: When does domestic violence equate with parental failure to protect?', Journal of Interpersonal Violence, 18(4), pp.338-355.

Kolbo, J.R., Blakely, E.H., and Engleman, D. (1996) 'Children who witness domestic violence: A review of empirical literature', Journal of Interpersonal Violence, 11(2), pp.281-293.

Krugman, R.D. (2018) 'The More We Learn, the Less We Know: A Brief History of the Field of Child Abuse and Neglect' in Kilka, J.B. and Conte, J.R. (eds.). The APSAC Handbook on Child Maltreatment. 4th ed. Thousand Oaks, CA: Sage Publications, pp.1-13.

Mason, M.A. (1994) From father's property to children's rights: The history of child custody in the United States. New York, NY: Columbia University Press.

Montgomery, J. (1988) 'Children as property?', The Modern Law Review, 51(3), pp.323-342. 
Myers, J.E. (2008) 'A short history of child protection in America', Family Law Quarterly, 42(3), pp.449-464.

Olafson, E., Corwin, D.L. and Summit, R.C. (1993) 'Modern history of child sexual abuse awareness: Cycles of discovery and suppression', Child Abuse and Neglect, 17(1), pp.7-24.

Parton, N. (1979) 'The natural history of child abuse: A study in social problem definition', The British Journal of Social Work, 9(4), pp.431-451.

Reid-Merritt, P. (2010) Righteous self-determination: The Black social work movement in America. Baltimore, MD: Imprint Editions

Roberts, D. (2002) Shattered bonds: The color of child welfare. New York, NY: Basic Books

US Senate. Committee on Health, Education, Labor and Pensions. CAPTA Reauthorization Act of 2010. (2010) (111-378). Washington: Government Printing Office.

Sarri, R. and Finn, J. (1992) 'Child welfare policy and practice: Rethinking the history of our certainties', Children and Youth Services Review, 14(3-4), pp.219-236

Thornton, V. (2014) 'Understanding the emotional impact of domestic violence on young children', Educational and Child Psychology, 31(1), pp.91-100.

Xu, Y., Ahn, H. and Keyser, D. (2020) 'Measuring familycentered practice in child welfare', Families in Society, 101(2), pp.148-166.

Woodhouse, B. (1992) 'Who owns the child? Meyer and pierce and the child as property', William and Mary Law Review, 33(4), pp.995-1122. 